\title{
CD105 positive neovessels are prevalent in early stage carotid lesions, and correlate with the grade in more advanced carotid and coronary plaques
}

\author{
Journal of Angiogenesis Research 1:6 I DOI: 10.1186/2040-2384-1-6 I C Li et al.; licensee Publiverse \\ Online S.R.L. 2009 \\ Received: 10 Jul 2009 | Accepted: 21 Jul 2009 | Published: 21 Jul 2009 \\ Luque Ana, Slevin Mark, Turu Marta M, Juan-Babot Oriol, Badimon Lina, Krupinski Jerzy ${ }^{\circledR}$ \\ ${ }^{+}$Contributed equally ${ }^{@}$ Corresponding author
}

\begin{abstract}
Background

Previous studies have demonstrated that expression of CD105 is a sensitive marker and indicator of endothelial cell/microvessel activation and proliferation in aggressive solid tumour growth and atherosclerotic plaque lesions. Since intimal neovascularization contributes significantly to subsequent plaque instability, haemorrhage and rupture.
\end{abstract}

\section{Methods}

We have used immunohistochemical analysis to investigate the expression of CD105-positive vessels in both large (carotid) and medium calibre (coronary and middle cerebral artery, MCAs) diseased vessels in an attempt to identify any correlation with plaque growth, stage and complication/type.

\section{Results}

Here we show, that carotid arteries expressed intimal neovascularization associated with CD105-positive endothelial cells, concomitant with increased inflammation in early stage lesions, preatheroma (I-III) whilst they were not present in coronary plaques of the same grade. Some of these CD105-positive neovessels were immature, thin walled and without smooth muscle cell coverage making them more prone to haemorrhage and rupture. In high-grade lesions, neovessel proliferation was similar in both arterial types and significantly higher numbers of CD105-positive vasa vasorum were associated with plaque regions in coronary arteries. In contrast, although the MCAs exhibited expanded intimas and established plaques, there were very few CD105 positive neovessels.

\section{Conclusion}

Our results show that CD105 is a useful marker of angiogenesis within adventitial and intimal vessels and suggest the existence of significant differences in the pathological development of atherosclerosis in separate vascular beds which may have important consequences when considering management and treatment of this disease.

\section{Background}

Atherosclerosis is strongly associated with symptomatic cardiovascular disease and ischemic stroke, which are the leading causes of death and disability in the Western world. Atherosclerosis is considered to be a multifactorial disease with numerous risk factors including smoking, alcohol abuse, hypertension, diabetes mellitus, dyslipidemia and infection with microorganisms including Chlamydia pneumoniae [1]. All these factors involve complex interactions between pathways associated with inflammation, lipid metabolism, 
coagulation, hypoxia, apoptosis and the immune response. Atherosclerotic plaque instability is also an independent risk factor for ischemic stroke [ 2- 5]. In the absence of atherosclerosis, normal vessel walls have a microvasculature that is confined to the adventitia and outer media [6]. Intimal neovascularization of human arteries was first noticed and linked with atherosclerosis and intimal thickening by Koester in 1876 [ 7]. As the disease progresses, the intima thickens and oxygen diffusion is impaired [ 8]. In atherosclerotic plaques angiogenesis allows the formation of new microvessels to maintain oxygen and nutrient supply for vascular cells [ 5]. Neovessel growth occurs in regions of atherosclerotic lesions undergoing remodelling, plaque 'shoulders' prone to rupture. There is a cellular inflammatory response to injury in the early remodelling stage of repair, in which angiogenesis may also play an important role. In pathological conditions, neovascularization varies from a transient contribution to healing to a permanent contribution for tissue regeneration [9].

A variety of studies, suggest that neovascularization contributes to the growth of atherosclerotic lesions, is associated with symptomatic carotid disease, and is a key factor in plaque de-stabilization leading to rupture [ 10, 11]. Some of the neovessels are irregular and immature, similar to those found in solid tumour vascularization and therefore may contribute to the development of intraplaque haemorrhage and subsequently plaque instability $[5,7-9,12]$.

CD105 is a homodimeric integral membrane glycoprotein composed of disulfide-linked subunits of 90-95 kDa [ $13]$ and is a component of the transforming growth factor- $\beta$ receptor complex. CD105 is predominantly expressed in angiogenic endothelial cells and is up-regulated during hypoxia via the hypoxia-inducible factor-1 $\alpha$ which directly binds to the hypoxia response element in the CD105 promoter [ 14, 15]. CD105 is a sensitive marker for identification of tumour neovascularization, growth and prediction of outcome [ 16, 17]. CD105 is also sensitive marker and much more specific than CD31 or TGF- $\beta 1$ for assessing neovascularization in atherosclerotic plaques $[18,19]$, whilst levels of circulating soluble CD105 can accurately predict the presence of unstable plaques and even plaque rupture [20].

Here, we visualised CD105-positive vessels to ascertain the density of neovessels and the different vessel morphology within the neointima's of large vessel (carotid) and smaller calibre coronary and middle cerebral artery plaques in order to estimate the role of angiogenesis in different stages of development of atherosclerotic lesion from different vascular beds with known histological differences.

\section{Methods}

\section{Carotid and coronary specimens and anatomo-pathology}

We included 38 human carotid arteries with low to moderate stenosis (less than $50 \%$ by EcoDoppler imaging, angio-RM or angio-TAC), 20 MCAs and 32 coronary arteries obtained as vascular transplants from organ donors and post-mortem autopsies, Table 1. Carotid arteries, including the common carotid artery, and a large portion of internal and external carotids were excised by a vascular surgeon as a part of a standard procedure for organ transplantation. There was no time delay as the other organs were removed simultaneously. The arteries were removed, immediately rinsed in sterile $0.9 \%$ saline, snap-frozen in liquid nitrogen and stored at $-80^{\circ} \mathrm{C}$.

\section{Table 1}

\begin{tabular}{|c|c|c|c|c|}
\hline Feature & Carotids $(n=38)$ & $\operatorname{MCA}(n=20)$ & Coronaries $(n=32)$ & P-value \\
\hline Age $($ Mean \pm SD) & $67 \pm 15^{*}$ & $69 \pm 15^{\dagger}$ & $52.3 \pm 10.8 * \dagger$ & 0.000 \\
\hline $\operatorname{Sex}(\hat{o} /$ 우 $)$ & $25 / 13$ & $14 / 6$ & $25 / 6$ & NS \\
\hline $\mathrm{WBC} \times 10^{9} / \mathrm{L}($ Mean $\pm \mathrm{SD})$ & $12.3 \pm 10.0$ & $10.9 \pm 6.1$ & $7.6 \pm 2.1$ & NS \\
\hline Glucose $($ Mean \pm SD) $(\mathrm{mmol} / \mathrm{l})$ & $6.7 \pm 2.0$ & $9,1 \pm 5,4^{\dagger}$ & $5.7 \pm 0.9^{\dagger}$ & 0.026 \\
\hline Total cholesterol $($ Mean \pm SD) $(\mathrm{mmol} / \mathrm{l})$ & $3.4 \pm 1.0 *$ & $4.6 \pm 1.7$ & $5.3 \pm 2.0^{*}$ & 0.003 \\
\hline HTA n, (\%) & $15(39.5)$ & $13(65)$ & $5(16.1)$ & 0.001 \\
\hline $\mathrm{DM} n,(\%)$ & $8(21.1)$ & $6(30)$ & $4(12.9)$ & NS \\
\hline DLP n, $(\%)$ & $9(23.7)$ & $6(30)$ & $15(48.4)$ & NS \\
\hline Smoking $\mathrm{n},(\%)$ & $9(23.7)$ & $11(55)$ & $23(74.2)$ & 0.000 \\
\hline Alcohol abuse $\mathrm{n},(\%)$ & $8(21.1)$ & $5(25)$ & $14(45.2)$ & NS \\
\hline CAD n, $(\%)$ & $8(22.2)$ & $5(25)$ & $10(32.3)$ & NS \\
\hline Statins $n,(\%)$ & $5(20.8)$ & $2(10)$ & $9(29)$ & NS \\
\hline Antiplatelets $\mathrm{n},(\%)$ & $4(16.7)$ & $6(30)$ & $4(12.9)$ & NS \\
\hline Rasb n, (\%) & $9(37.5)$ & $6(30)$ & $12(38.7)$ & NS \\
\hline
\end{tabular}


MCA, middle cerebral arteries; WBC, white blood cells; HTA, hypertension; DM, diabetes mellitus; DLP, dyslipemia; CAD, coronary artery disease; Rasb, renin angiotensin system blockers;

* Statistic significant between these groups; NS, not significant

Patient's clinical data

Prior to experimentation the arteries were fixed for 24 hours in buffered formalin, briefly decalcified to remove excess calcium and embedded in paraffin. Sections $(5 \mu \mathrm{m})$ were cut on a microtome. Plaque morphology was evaluated by analysis of haematoxylin-eosin stained serial sections obtained at intervals of $3 \mathrm{~mm}$. Carotid, coronaries and MCA plaques were classified according to the American Heart Association (AHA) [21], with some modifications in the case of carotid arteries because points of calcification are common in normal carotid arteries. Representative sections were used for immunohistochemistry. The study was approved by the local ethical committee in accordance with institutional guidelines and the family's written informed consent was obtained.

\section{Immunohistochemical analysis}

Paraffin-processed sections ( $5 \mu \mathrm{m})$ were deparaffinized in xylene and rehydrated in graded ethanol solutions. Slides were then rinsed in distilled water and treated with $10 \%$ hydrogen peroxide in methanol (30 minutes at RT) to remove endogenous peroxidase activity. Sections were blocked with a 5\% of normal serum in PBS-tween $0.1 \%$ (30 minutes at RT). Slides with the arterial specimens were then incubated with the specified dilution of primary antibody anti-CD105 (1:50, goat polyclonal antibody, R\&D Systems, Abingdon, Oxford, UK) or antiCD34 (1:50, mouse monoclonal antibody, NovoCastra, Newcastle, UK) overnight at $4^{\circ} \mathrm{C}$. After washing 3 times in PBS, biotinylated secondary antibody (Vector Laboratories) was used at a 1:200 dilution, and incubated at RT for 1 hour. After rinsing in PBS, standard Vectastain (ABC) avidin-biotin peroxidase complex (Vector Laboratories) was applied, and the slides were incubated at RT for 30 minutes. Colour was developed using 3, 3'diaminobenzidine (DAB) and sections were counterstained with haematoxylin before dehydration, clearing, and mounting. Negative controls in which the primary antibody was replaced with PBS were used to test for nonspecific binding (data not included). All immunostaining was assessed by 2 investigators simultaneously using a double-headed light microscope. Results are presented in Tables 2, 3and 4.

\section{Table 2}

\begin{tabular}{l|c|c}
\hline & CD34 $^{\circ}$ neovessels $/ \mathbf{m m}^{2}$ & CD105 $\mathbf{N}^{\circ}$ neovessels $/ \mathbf{m m}^{2}$ \\
\hline Carotids $(\mathrm{n}=4)$ & $7.9 \pm 5.2$ & $1.6 \pm 1.1$ \\
Coronaries $(\mathrm{n}=4)$ & $8.8 \pm 6.6$ & $2.1 \pm 1.6$ \\
\hline
\end{tabular}

Values are mean \pm SD

$\mathrm{N}^{\circ}$ neovessels $/ \mathrm{mm}^{2}$ stained with anti-CD105 compared with anti-CD34 in selected cases

Table 3

\begin{tabular}{c|c|c}
\hline & $N^{\circ}$ neovessels/mm & Neointima thickness $(\boldsymbol{\mu m})$ \\
\hline Carotid AHA classification & & \\
Early (I-III) $\mathrm{n}=21$ & $0.04 \pm 0.2$ & $626.2 \pm 876.5$ \\
Intermediate(IV-Va) $\mathrm{n}=17$ & $1.8 \pm 2.4$ & $1925.7 \pm 882.5$ \\
$P$-value & 0.000 & 0.000 \\
Coronaries AHA classification & & \\
Early (I-III) $\mathrm{n}=11$ & 0.0 & $512.6 \pm 327.6$ \\
Intermediate (IV-Va) $\mathrm{n}=11$ & $1.3 \pm 1.9$ & $1141.9 \pm 458.8$ \\
Advanced (Vb-VI) $\mathrm{n}=10$ & $5.9 \pm 7.4$ & $1561.7 \pm 1433.6$ \\
$P$-value & 0.000 & 0.003 \\
MCA $\quad$ & 0.0 & $129.2 \pm 176.7$ \\
Early (I-III) $\mathrm{n}=12$ & $0.2 \pm 0.4$ & 0.001 \\
Intermediate (IV-Va) $\mathrm{n}=8$ & $\mathrm{NS}$ & \\
$P$-value &
\end{tabular}

Values are mean \pm SD; MCA, middle cerebral arteries; NS, not significant

$\mathrm{N}^{\circ}$ neovessels $/ \mathrm{mm}^{2}$ in the neointima and Maximum thickness of neointima $(\mu \mathrm{m})$ of different arteries 


\begin{tabular}{|c|c|c|c|}
\hline AHA classification & $\begin{array}{c}N^{\circ} \text { neovessels } / \mathrm{mm}^{2} \text { plaque } \\
\text { area }\end{array}$ & $\begin{array}{r}N^{\circ} \text { neovessels } / \mathrm{mm}^{2} \text { non-plaque } \\
\text { area }\end{array}$ & p-value \\
\hline \multicolumn{4}{|l|}{ Carotids } \\
\hline Early (I-III) $n=21$ & $2.9 \pm 3.2$ & $2.4 \pm 2.4$ & NS \\
\hline Intermediate(IV-Va) $n=17$ & $3.0 \pm 2.1$ & $2.1 \pm 2.2$ & NS \\
\hline \multicolumn{4}{|l|}{ Coronaries } \\
\hline Early (I-III) $n=11$ & $3.7 \pm 4.4$ & $1.7 \pm 2.5$ & NS \\
\hline $\begin{array}{l}\text { Intermediate }(\mathrm{IV}-\mathrm{Va}) \mathrm{n}= \\
11\end{array}$ & $2.3 \pm 1.6$ & $0.8 \pm 1.3$ & 0.003 \\
\hline $\begin{array}{l}\text { Advanced }(\mathrm{Vb}-\mathrm{VI}) \mathrm{n}= \\
0\end{array}$ & $3.0 \pm 2.8$ & $2.0 \pm 1.9$ & NS \\
\hline
\end{tabular}

Values are mean $\pm \mathrm{SD}$; NS, not significant

$\mathrm{N}^{\circ}$ neovessels $/ \mathrm{mm}^{2}$ in the adventitia of different arteries

\section{Quantitative analysis}

Manual microvessel counting was performed by a single observer. All neovessels of the neointimal and adventitial areas were counted using fields at $\times 200$ magnification with the Olympus Vanox AHBT3 microscope in all type of arteries. The density of neovessels of the adventitial layer containing plaque was compared to the non-containing plaque area. Each microvessel was defined as a lumen surrounded by a layer of endothelial cells highlighted by immunostaining with anti-CD34 antibody and each active neovessel was defined as positive with anti-CD105 antibody. The total microvessel count for each sample section was divided by the area covered by that section. Microvessel counts were expressed as microvessels per square millimetre of plaque sectional area. The morphometric study was performed using a Sony DXC-S500 camera and processing performed using the Visilog 4.1.5 (Noesis) program.

In this study, we compared the number of anti-CD105 and anti-CD34 positive neovessels per square millimetre in the neointima of selected carotids $(n=4)$ and coronaries $(n=4)$ to confirm the selectivity of the antibodies. The number of microvessesls stained with anti-CD34 antibody was higher than anti-CD105 ones in both types of arteries. Results are presented in Table 2. Thirty eight carotids, 32 coronaries and 20 MCAs were subsequently analyzed for the expression of CD105.

\section{Statistical analysis}

All statistical analysis was performed with the SPSS for Windows statistical software program (version 15.0, SPSS Inc.). One-way ANOVA was used to assess the statistical significance of patient's clinical data and differences between the three groups of arteries in relation to quantitative variables. The Chi-Square test was used for measurement of differences in qualitative variables. Differences in the number of neovessels in the intimas between carotid and coronary arteries was analysed using the Wilcoxon non-parametric test. Differences in the number of neovessels per square millimetre in the neointima and the type of lesion or the maximum thickness of neointima $(\mu \mathrm{m})$ were analysed with the Kruskal-Wallis test. Means between numbers of neovessels in different areas of the adventitia were compared using the Student-t test. Statistical significance was assumed when $P<0.05$.

\section{Results}

A summary of the patient's basic clinical data, derived from samples which were obtained before death, is presented in Table 1. Haematoxylin and eosin sections were classified using the AHA system as; type I, early lesion; II, fatty streaks; III, intermediate lesion; IV, atheroma; Va, fibroatheroma; Vb, calcific lesion; Vc, fibrotic lesion and VI, complicated lesion [21]. Plaque AHA classification and phenotype characteristics such as inflammation or calcification are presented in Additional file 1.

\section{Neointimal plaque vascularity}

Of the 38 carotid and 32 coronary arteries, we compared the number of anti-CD105 and anti-CD34 positive neovessels per square millimetre in the neointima of selected carotids $(n=4)$ and coronaries $(n=4)$. The number of microvessesls stained with anti-CD34 antibody was higher than anti-CD105 ones in both types of arteries. Results are presented in Table 2.

In the 38 carotids, 32 coronaries and 20 MCAs analyzed for CD105 expression, there was an increase of the maximum thickness of the neointima $(\mu \mathrm{m})$ in more advanced lesions compared with intermediate and/or early lesions $(\mathrm{p}<0.05)$. There was a significant increase in plaque microvessel density with increased lesion severity 
in coronary arterial plaques and in carotid arteries $(\mathrm{p}<0.05)$. There were significantly more microvessels per square millimetre in both intermediate and advanced lesions compared with early lesions. Results are presented in Table 3. Few neovessels were observed in the neointima's of intermediate MCAs lesions; however intense expression of CD105 was seen in the intraluminal endothelial cells in all lesion types.

\section{Adventitial vasa vasorum concentration in plaque containing and plaque free regions}

The median total microvessel count per square millimetre in adventitia where there was visible intraluminal plaque did not differ significantly with that of plaque free regions in early or intermediate stage carotid arteries. However there was a significant correlation between CD105-positive vasa vasorum in advanced plaque regions of coronary arteries $(\mathrm{p}=0.003)$. Results are presented in Table 4 .

\section{Discussion}

In this study, we have identified significantly increased CD105-positive microvessel density with increasing grade of atherosclerotic lesion in carotid arteries with stenosis $<50 \%$ and in coronary arteries. Increased CD105positive intimal neovessels were demonstrated previously by Li et al [ 18], whilst they also showed that CD105 staining was almost absent in normal arteries. Since we previously showed that cells (myoblasts) which do not normally express CD105, when transfected with this gene, exhibited increased cellular attachment, spreading, survival and growth concomitant with increased phosphorylation of JNK [ 15], and that CD105 expression is also up-regulated by hypoxia and TGF- $\beta$, also features of plaque development [ 22], the current observations suggest that CD105 expression is associated with active angiogenic neovascularization in these lesions. In selected cases we compared CD105 staining with CD34 positive vessels. There was less CD105 positive vessels, further suggesting that this marker is selective for active or new vessels.

There was a statistically significant increase in the maximum thickness of the neointima with increasing grade of lesion in coronary, carotid and MCA arteries. This increase correlated with an increase in the expression of CD105-positive microvessels. The early stage (grade I-III) coronary arteries generally contained stable uncomplicated plaques with few areas of inflammation. This was in contrast to the larger calibre carotid arteries which exhibited more complex heterogeneous features with more evidence of inflammation and the presence of CD105-positive vessels in grade I-III + lesions. This adds more weight to the evidence suggesting significantly different developmental profiles between carotid and coronary artery diseases with that of the carotid arteries demonstrating higher angiogenic activity, possibly in part due to the increased inflammatory infiltration and ultimately resulting in earlier production of unstable regions prone to haemorrhage and rupture $[1,12]$. The prevalence of neovascularization in carotid arteries of symptomatic patients could help to explain the more rapid development of unstable lesion and subsequent thrombosis. Further, we know from the clinical experience that patients with low to moderate carotid stenosis suffer strokes or transient ischaemic attacks. These often are classified as of unknown origin if screening for cardiac source of emboli is negative and only non-significant intracranial or extracranial stenosis is detected [ 23,24]. Quickly evolving carotid lesions without important lumen occlusion may be at least partially responsible for these events.

In more advanced plaques (grade IV-V) there remained a notable difference between coronary and carotid vessels with respect to the numbers of neointimal CD105-positive microvessels and this was associated with larger intimal thickness in the carotid arteries. There were no notable differences in plaque CD105-positive vessel density in coronary or carotid arteries from patients who had been undergoing treatment with antiplatelets and statins and the others.

Atherosclerosis in the intracranial arteries is less studied, although stenosis of MCA is a common cause of stroke in some populations [25]. The exact frequency and role of intracranial artery plaques in living patients with stroke is still unknown in Caucassian population [ 26]. Intracranial plaques and stenoses is highly prevalent in fatal stroke, however, some of the reported stenoses graded $30 \%$ to $75 \%$ may be causal and correspond to superimposed clot on ulcerated plaque. In our series MCA showed evidence of intimal angiogenesis. This is in contrast to some of the studies which reported higher prevelance of neovasculature in plaques associated with stroke [ 25]. However, the authors did not use any marker to show neovessels and overall number of plaques with neovasculature was low. Plaques developing in the intracranial arteries can probably survive and obtain nutrients by diffusion from the existing adventitia. However the existence of CD105-positive vasa vasorum allows for the possibility that plaque development still activates these vessels and that they are affected by secretion of pro-angiogenic molecules from the intimal site. It would be interesting to compare and identify the mitogenic factors expressed in different vascular beds.

Our results indicate that intraplaque biomarkers, rather than conventional risk factors, may reveal clinical and radiological differences between patients with carotid and MCA atherosclerosis. Plaques associated with MCA atherosclerosis may be more stable than those associated with carotid atherosclerosis [ 27]. 
Perhaps surprisingly, there were no significant differences between the numbers of CD105-positive vessels in the adventitia adjacent to the plaque area compared with non-plaque containing regions in carotid arteries. Since the number of CD105-positive vessels was increased significantly in all areas of the adventitia, it is possible that a more general activation of the vasa vasorum occurs and neointimal infiltrating endothelial cells are derived from a more widespread region. This was demonstrated recently by Coli et al [28], who showed that the number of CD31/CD34 positive vasa vasorum microvessels correlated with plaque echolucency, although not with the degree of stenosis. In contrast, the numbers of vasa vasorum CD105-positive vessels correlated strongly with areas of plaque remodelling suggesting a more focussed process of remodelling.

In the neointima we observed abnormal morphology in many of the neovessels even in some of the early stage grade II-III carotid lesions. Some of the vessels demonstrated an elongated appearance but remained patent whilst others were more irregular, multilobular and often collapsed and non-functional. These immature vessels, similar to those identified in growing tumours [29] are more prone to rupture and haemorrhage. Dunmore et al [ 3] showed that dilated, highly irregular multilobular vessels were found almost exclusively in carotid plaques from symptomatic patients and not in asymptomatic ones. The vessels generally lacked smooth muscle cells, were immature and also existed in regions rich in VEGF-containing macrophages. We also showed that the majority of CD105-positive vessels were thin walled and immature suggesting they were undergoing angiogenesis and/or maturation associated with cellular activation.

Endoglin is a component of the TGF $\beta$ receptor complex expressed mainly on the surface of endothelial cells. TGF $\beta$ has notable effects on cell proliferation, differentiation, adhesion, migration, and extracellular matrix production, as well as other activities [ 30]. Endoglin binds to members of the TGF $\beta$ superfamily and modulates cellular responses to TGF- $\beta 1$. The growth factor TGF- $\beta 1$ is involved in the pathogenesis of atherosclerosis through its pleiotropic effects [ 31]. Some reports show anti-atherogenic properties to TGF- $\beta 1$ [ 32, 33], whereas others show that it has atherogenic properties [ 34,35$]$. Piao et al found an increased expression of TGF- $\beta 1$ in atherosclerotic lesions and an especially strong over-expression and higher expression rate in the advanced lesions, suggesting that TGF- $\beta 1$ participates in the formation of early lesions and the progression to advanced lesions [ 22]. CD105 may initiate its effects in atherosclerosis at an early stage through interaction with TGF $\beta$, but we do not know if the expression of these proteins is causative or a result of the atherogenesis.

It could be useful in a therapeutic setting to differentiate perhaps with specific markers and imaging, patent functional and stable vessels from mal-formed, leaky and unstable ones liable to haemorrhage. Future treatment aimed at stabilization of immature vessels could help in the control of developing lesions.

Additional file 1: Plaque AHA classification and phenotype characteristics. AHA classification and phenotype characteristics of carotid, coronary and middle cerebral artery plaques. (XLS $36 \mathrm{~KB}$ )

\section{Declarations}

\section{Acknowledgements}

This work was supported by grant: SAF 2006-07681 from the Ministerio de Educación y Ciencia (MEC) to JK.

\section{Authors' original submitted files for images}

Below are the links to the authors' original submitted files for images.

Authors' original file for figure 1

Authors' original file for figure 2

Authors' original file for figure 3

Authors' original file for figure 4

\section{Competing interests}

The authors declare that they have no competing interests.

\section{Authors' contributions}

AL carried out the histology and immunohistochemistry studies, performed the statistical analysis and drafted the manuscript. MS carried out the iquantification studies and drafted the manuscript. MMT carried out the histology studies. OJB carried out the histology and immunohistochemistry studies. LB participated in its design and 
coordination. JK participated in the design and coordination of the study, and drafted the manuscript. All authors read and approved the final manuscript.

\section{References}

1. Krupinski J, Font A, Luque A, Turu M, Slevin M. Angiogenesis and inflammation in carotid atherosclerosis. Front Biosci. 2008;13:6472-6482.

View Article Google Scholar

2. McCarthy MJ, Loftus IM, Thompson MM, Jones L, London NJ, Bell PR, Naylor AR, Brindle NP. Angiogenesis and the atherosclerotic carotid plaque: an association between symptomatology and plaque morphology. J Vasc Surg. 1999;30:261-268.

View Article Google Scholar

3. Dunmore BJ, McCarthy MJ, Naylor AR, Brindle NP. Carotid plaque instability and ischemic symptoms are linked to immaturity of microvessels within plaques. J Vasc Surg. 2007;45:155-159. View Article Google Scholar

4. Mofidi R, Crotty TB, McCarthy P, Sheehan SJ, Mehigan D, Keaveny TV. Association between plaque instability, angiogenesis and symptomatic carotid occlusive disease. Br J Surg. 2001;88:945-950.

View Article Google Scholar

5. Mofidi R, Powell TI, Crotty T, Mehigan D, Macerlaine D, Keaveny TV. Angiogenesis in carotid atherosclerotic lesions is associated with timing of ischemic neurological events and presence of computed tomographic cerebral infarction in the ipsilateral cerebral hemisphere. Ann Vasc Surg. 2008;22:266-272.

View Article Google Scholar

6. O'Brien ER Garvin MR Dev R Stewart DK Hinohara T Simpson JB Schwartz SM Angiogenesis in human coronary atherosclerotic plaques Am J Pathol 19941458838941887321

7. Zhang Y Cliff WJ Schoefl GI Higgins G Immunohistochemical study of intimal microvessels in coronary atherosclerosis Am J Pathol 19931431641721886935

8. Moreno PR, Purushothaman KR, Sirol M, Levy AP, Fuster V. Neovascularization in human atherosclerosis. Circulation. 2006;113:2245-2252.

View Article Google Scholar

9. Moreno PR, Purushothaman KR, Fuster V, Echeverri D, Truszczynska H, Sharma SK, Badimon JJ, O'Connor WN. Plaque neovascularization is increased in ruptured atherosclerotic lesions of human aorta: implications for plaque vulnerability. Circulation. 2004;110:2032-2038.

View Article Google Scholar

10. Khurana R, Simons M, Martin JF, Zachary IC. Role of angiogenesis in cardiovascular disease: a critical appraisal. Circulation. 2005;112:1813-1824.

View Article Google Scholar

11. Tureyen K, Vemuganti R, Salamat MS, Dempsey RJ. Increased angiogenesis and angiogenic gene expression in carotid artery plaques from symptomatic stroke patients. Neurosurgery. 2006;58:971977.

View Article Google Scholar

12. Ribatti D, Levi-Schaffer F, Kovanen PT. Inflammatory angiogenesis in atherogenesis--a doubleedged sword. Ann Med. 2008;40:606-621.

View Article Google Scholar

13. Barbara NP, Wrana JL, Letarte M. Endoglin is an accessory protein that interacts with the signaling receptor complex of multiple members of the transforming growth factor-beta superfamily. J Biol Chem. 1999;274:584-594. 
14. Duff SE, Li C, Garland JM, Kumar S. CD105 is important for angiogenesis: evidence and potential applications. Faseb J. 2003;17:984-992.

View Article Google Scholar

15. Guo B, Kumar S, Li C, Slevin M, Kumar P. CD105 (endoglin), apoptosis, and stroke. Stroke. 2004;35:e94-95.

View Article Google Scholar

16. Dhakal HP, Naume B, Synnestvedt M, Borgen E, Kaaresen R, Schlichting E, Wiedswang G, Bassarova A, Giercksky KE, Nesland JM. Vascularization in primary breast carcinomas: its prognostic significance and relationship with tumor cell dissemination. Clin Cancer Res. 2008;14:2341-2350.

View Article Google Scholar

17. Marioni G, Giacomelli L, D'Alessandro E, Staffieri C, Guzzardo V, Staffieri A, Blandamura S. Laryngeal carcinoma recurrence rate and disease-free interval are related to CD105 expression but not to vascular endothelial growth factor 2 (Flk-1/Kdr) expression. Anticancer Res. 2008;28:551-557. View Article Google Scholar

18. Li C, Mollahan P, Baguneid MS, McMahon RF, Kumar P, Walker MG, Freemont AJ, Kumar S. A comparative study of neovascularisation in atherosclerotic plaques using CD31, CD105 and TGF beta 1. Pathobiology. 2006;73:192-197.

View Article Google Scholar

19. Middleton J, Americh L, Gayon R, Julien D, Mansat M, Mansat P, Anract P, Cantagrel A, Cattan P, Reimund JM, et al. A comparative study of endothelial cell markers expressed in chronically inflamed human tissues: MECA-79, Duffy antigen receptor for chemokines, von Willebrand factor, CD31, CD34, CD105 and CD146. J Pathol. 2005;206:260-268.

View Article Google Scholar

20. Cui S, Lu SZ, Chen YD, He GX, Meng LJ, Liu JP, Song ZY, Liu XL, Song XT, Ge CJ, Liu H. Relationship among soluble CD105, hypersensitive C-reactive protein and coronary plaque morphology: an intravascular ultrasound study. Chin Med J (Engl). 2008;121:128-132.

View Article Google Scholar

21. Virmani R, Kolodgie FD, Burke AP, Farb A, Schwartz SM. Lessons from sudden coronary death: a comprehensive morphological classification scheme for atherosclerotic lesions. Arterioscler Thromb Vasc Biol. 2000;20:1262-1275.

View Article Google Scholar

22. Piao M, Tokunaga O. Significant expression of endoglin (CD105), TGFbeta-1 and TGFbeta R-2 in the atherosclerotic aorta: an immunohistological study. J Atheroscler Thromb. 2006;13:82-89.

View Article Google Scholar

23. Caplan LR, Hennerici M. Impaired clearance of emboli (washout) is an important link between hypoperfusion, embolism, and ischemic stroke. Arch Neurol. 1998;55:1475-1482.

View Article Google Scholar

24. Wong KS, Li H, Lam WW, Chan YL, Kay R. Progression of middle cerebral artery occlusive disease and its relationship with further vascular events after stroke. Stroke. 2002;33:532-536.

View Article Google Scholar

25. Chen XY, Wong KS, Lam WW, Zhao HL, Ng HK. Middle cerebral artery atherosclerosis: histological comparison between plaques associated with and not associated with infarct in a postmortem study. Cerebrovasc Dis. 2008;25:74-80.

View Article Google Scholar

26. Mazighi M, Labreuche J, Gongora-Rivera F, Duyckaerts C, Hauw JJ, Amarenco P. Autopsy prevalence of intracranial atherosclerosis in patients with fatal stroke. Stroke. 2008;39:1142-1147. 
27. Bang OY Lee PH Yoon SR Lee MA Joo IS Huh K Inflammatory markers, rather than conventional risk factors, are different between carotid and MCA atherosclerosis J Neurol Neurosurg Psychiatry 200576112811341739734 10.1136/jnnp.2004.054403

28. Coli S, Magnoni M, Sangiorgi G, Marrocco-Trischitta MM, Melisurgo G, Mauriello A, Spagnoli L, Chiesa R, Cianflone D, Maseri A. Contrast-enhanced ultrasound imaging of intraplaque neovascularization in carotid arteries: correlation with histology and plaque echogenicity. J Am Coll Cardiol. 2008;52:223-230.

View Article Google Scholar

29. Miyagami M, Katayama Y. Angiogenesis of glioma: evaluation of ultrastructural characteristics of microvessels and tubular bodies (Weibel-Palade) in endothelial cells and immunohistochemical findings with VEGF and p53 protein. Med Mol Morphol. 2005;38:36-42.

View Article Google Scholar

30. Massaje J. The transforming growth factor- $\beta$ family. Anni Rev Cell Biol. 1990;6:597-641 . View Article Google Scholar

31. Li CG, Bethell H, Wilson PB, Bhatnagar D, Walker MG, Kumar S. The significance of CD105, TGF $\beta$ and CD105/TGF $\beta$ complexes in coronary artery disease. Atherosclerosis. 1999;152:249-256.

View Article Google Scholar

32. Grainger DJ, Kemp PR, Metcalfe JC, Liu AC, Lawn RM, Williams NR, Grace AA, Schofield PM, Chauhan A. The serum concentration of active transforming growth factor-beta is severely depressed in advanced atherosclerosis. Nat Med. 1995;1:74-79.

View Article Google Scholar

33. Grainger DJ, Kemp PR, Liu AC, Lawn RM, Metcalfe JC. Activation of transforming growth factorbeta is inhibited in transgenic apolipoprotein(a) mice. Nature. 1994;370:460-462.

View Article Google Scholar

34. Nikol S Isner JM Pickering JG Kearney M Leclerc G Weir L Expression of transforming growth factor-beta is increased in human vascular restenosis lesion J Clin Invest 1992901582 1592443206 10.1172/JCI116027

35. Majesky MW Linder V Twardzik DR Schwartz SM Reidy MA Production of transforming growth factor beta 1 during repair of arterial injury J Clin Invest 199188904910295478 $10.1172 /$ JCI115393 